Article

\title{
The Effect of Off-Farm Employment on Forestland Transfers in China: A Simultaneous-Equation Tobit Model Estimation
}

\author{
Han Zhang ${ }^{1}$, Jari Kuuluvainen ${ }^{2}$ (D), Hongqiang Yang ${ }^{3}$ (D), Yi Xie ${ }^{4}$ and Can Liu ${ }^{1,5, *}$ \\ 1 College of Economics and Management, Northwest A\&F University, No. 3 Taicheng Road, \\ Yangling 712100, China; hanzhang32@126.com \\ 2 Department of Forest Sciences, University of Helsinki, P.O. Box 27, 00014 Helsinki, Finland; \\ jari.kuuluvainen@helsinki.fi \\ 3 College of Economics and Management, Nanjing Forestry University, No. 159 Longpan Road, \\ Nanjing 210037, China; yhqnfu@gmail.com \\ 4 College of Economics and Management, Beijing Forestry University, 35 Qinghua E Rd., WuDaoKou, \\ Haidian Qu, Beijing 100085, China; xybjfu@126.com \\ 5 Economic Development Research Center, State Forestry Administration of China, Beijing 100714, China \\ * Correspondence: liucansfa@126.com
}

Received: 1 August 2017; Accepted: 13 September 2017; Published: 16 September 2017

\begin{abstract}
China's new round tenure reform has devolved collective forests to individuals on an egalitarian basis. To balance the equity-efficiency dilemma, forestland transfers are highly advocated by policymakers. However, the forestland rental market is still inactive after the reform. To examine the role of off-farm employment in forestland transfers, a simultaneous Tobit system of equations was employed to account for the endogeneity, interdependency, and censoring issues. Accordingly, the Nelson-Olson two-stage procedure, embedded with a multivariate Tobit estimator, was applied to a nationally representative dataset. The estimation results showed that off-farm employment plays a significantly negative role in forestland rent-in, at the $5 \%$ risk level. However, off-farm activities had no significant effect on forestland rent-out. Considering China's specific situation, a reasonable explanation is that households hold forestland as a crucial means of social security against the risk of unemployment. In both rent-in and rent-out equations, high transaction costs are one of the main obstacles impeding forestland transfer. A remarkable finding was that forestland transactions occurred with a statistically significant factor equalization effect, which would be helpful to adjust the mismatched labor-land ratio and improve the land-use efficiency.
\end{abstract}

Keywords: collective forest tenure reform; forestland transfer; off-farm employment; simultaneous-equation Tobit model; efficiency

\section{Introduction}

China has approximately 120 million hectares of farmland, which is capable of feeding the Chinese population of 1.3 billion people (http:/ / www.forestry.gov.cn/portal/main/s/195/content-521780. html.). By contrast, with 303 million hectares of forestland, China cannot provide sufficient timber for domestic consumption, and its import dependency is high $(48.31 \%$ of the total consumption of timber in 2015) (http:/ / www.forestry.gov.cn/main/62/content-957369.html.). This highlights a lower efficiency of forestland cultivation than that of farmland. China's agricultural production and productivity experienced remarkable growth after an institutional shift from the collective system to the household-responsibility system in the early 1980s [1]. However, similar policies, named "the Three Fixes", were not implemented thoroughly in China's forestry sector, partly due to ecological considerations [2]. The forestry productivity has been severely impeded by institutional and regulatory 
barriers [3]. Therefore, a new round of tenure reform was initiated on collective forestland around 2003 [4], known as the collective forest tenure reform (CFTR). Two stages were involved: The first stage was called the main-body reform and involved contracting collective-owned forestland to individuals, with clarified and secure property rights for up to 70 years. The second stage is known as the supplementary reform or the concomitant reform, which entitles households to transferability, inheritance and mortgage rights [5]. Currently, the second-stage reform is still in progress.

In practice, the CFTR was conducted according to an egalitarian principle based on the family headcount. This may create a mismatch between households' production ability and forestland size. To address this mismatch, forestland transfer among households has been strongly advocated by the government. However, the State Forestry Administration (SFA) of China declared that only $2 \%$ of contracted forestland has been transferred between households, which is evidently less than the transfer of farmland (30.4\%) (http:/ / www.forestry.gov.cn/Zhuanti/content_lqgg/800410.html.). The incredibly low rate of transactions implies that the low efficiency of forestland management might not be considerably improved through the CFTR, as it is hard to believe that efficiency could be automatically reached under the egalitarian allocation scheme used in the CFTR. Therefore, to improve efficiency in forestry, there is a pressing need to identify the main determinants of forestland transfers.

Much literature has focused on China's farmland transfer, where off-farm employment is widely emphasized as one of its crucial determinants [6-12]. The rationale is intuitive: households own land only because the marginal income from farming cultivation is not less than that from their alternative income sources. This implies that the off-farm activity can be considered to play an important role in determining the land transfer decisions [13]. Unlike the abundance of farmland transfer studies, there seem to be only two papers so far on the forestland rental market and the related forestland transfer behavior (This argument is based on the search results from the Web of Science (https: / / apps.webofknowledge.com, accessed on 10 May 2017), using TOPIC: (forestland rental) and TOPIC: (China). Only papers written in English language and published in international journals are reviewed here.). With 222 households in the Zhejiang province, Xu et al. [14] examined the determinants of households' decisions on forestland transfers. They found that off-farm employment had significantly negative and positive effects, on rent-in and rent-out decisions, respectively (The term "rent-in" means an action to transfer in more forestland from other households, while the term "rent-out" refers to an action to lease out forestland to others. These two terms are commonly used in previous literature [7]). However, with a larger sample of 701 households from three provinces, Siikamäki et al. [15] found that the effect was significantly negative, no matter what the direction of the transfer.

More importantly, both Xu et al. [14] and Siikamäki et al. [15] neglected the potential endogeneity of off-farm employment. The forestland transfers and off-farm employment behaviors are decided endogenously and simultaneously by farmers' profit-maximization decisions, which require an estimation of the simultaneous-equation model. In a paper on farmland transfers, Feng and Heerink [8] realized this issue and employed a bivariate probit model to estimate a reduced form system of equations. The reduced form setup implies that only exogenous variables are included on the right-hand side of the equations, therefore, the effect of off-farm employment on land transfers cannot be estimated directly. Instead, they used the sign of the correlation coefficient between error terms to illustrate the relationship between these two behaviors. However, the setup of a bivariate model means that the correlation coefficient only indicates whether one equation is correlated with others. It does not produce the effect of one endogenous variable on other endogenous variables [16,17]. For instance, in a paper on household water expenditure, Yoo [18] found that the sign of the correlation coefficient between error terms of two behavioral equations and the sign of the effect between endogenous variables of these equations can be opposite. Hence, using the signs of the correlation coefficients to infer the effects of dependent variables on each other may be misleading. To obtain the effect of off-farm employment on forestland transfer, a structural form or simultaneous-equation system model should be established (Per Amemiya [16] and Roodman [19], we refer to the multivariate model in 
the sense that no endogenous variables appear on the right-hand sides of other equations, while we refer to the simultaneous system of equations if the endogenous variables are included in other equations. It can be found that the former model is a special case of the latter one.). Furthermore, the low occurrence of forestland transfer implies that the dependent variable is censored. Therefore, this paper employs a simultaneous-equation Tobit model to account for the endogeneity of off-farm work, the interdependency across different equations, and the limited dependent variables.

Given the contradicting results and shortcomings in the statistical inferences of the previous literature on forestland transfers, this paper aims to re-investigate the effect of off-farm employment on forestland transfers with a nationally representative dataset. The remainder of the paper is structured as follows. Section 2 presents the materials and methods, including the theoretical framework, estimation approach, data source and descriptive statistics. Section 3 reports the empirical results and discusses the findings. Section 4 concludes with policy implications.

\section{Materials and Methods}

\subsection{Theoretical Model}

For a representative household, the endowed amount of labor $(\bar{L})$ is allocated between forestland cultivation $\left(L_{F}\right)$ and off-farm work $\left(L_{O}\right)$ at an exogenously given wage $(w)$. The possibility of hired labor on forestland is excluded, as the local farm labor market is, in general, inactive and limited in China [20]. According to Favada et al. [21], the households' long-run forestry production function is specified as $f\left(L_{F}, A_{F}, Z\right) / T$ with standard properties, where $A_{F}$ represents forestland used in forestry production, vector $Z$ refers to households and village characteristics, and $T$ is the rotation age of forests (With regard to forestry production, the inputs of the current year will yield timber production after $T$ years. Theoretically, the harvesting can be sustainably continued under a normal forest, where the annual logging volume can be deemed to be $1 / T$ of the total output [22]). The existence of the forestland tenancy market implies that the cultivated forestland $A_{F}$ is not necessarily equal to the endowed area of forestland $(\bar{A})$. Besides the land rent $r$, leasing of land incurs an additional transaction cost (TC), which acts as a price wedge between the gain of renting out $(r-T C)$ and the cost of renting in $(r+T C)$. Let $A_{\text {in }}$ and $A_{\text {out }}$ denote the amount of forestland rent-in and rent-out, respectively. $p$ represents the price of forestry products. The household decision is to allocate the endowed labor and land to maximize the net benefits as follows (The agricultural production is not considered here. For this paper, the household survey is conducted in the major forestry producing regions, where the land cultivation is mainly related to forest management activities.):

$$
\begin{gathered}
\max _{L_{O}, A_{\text {in }}, A_{\text {out }}} p \times f\left(L_{F}, A_{F}, Z\right) / T+w \times L_{O}-A_{\text {in }} \times r_{\text {in }}+A_{\text {out }} \times r_{\text {out }} \\
\text { s.t. } A_{F}=\bar{A}+A_{\text {in }}-A_{\text {out }}, L_{F}+L_{O}=\bar{L} \\
r_{\text {in }}=r+T C, r_{\text {out }}=r-T C
\end{gathered}
$$

The first order conditions of Equation (1) yield the optimal allocation of labor and forestland, and suggest the following structural form system of equations:

$$
\begin{gathered}
A_{\text {in }}=A_{\text {in }}\left(A_{\text {out }}, L_{O} ; p, w, r, T C, \bar{L}, \bar{A}, Z, T\right) \\
A_{\text {out }}=A_{\text {out }}\left(A_{\text {in }}, L_{O} ; p, w, r, T C, \bar{L}, \bar{A}, Z, T\right) \\
L_{O}=L_{O}\left(A_{\text {in }}, A_{\text {out }} ; p, w, r, T C, \bar{L}, \bar{A}, Z, T\right)
\end{gathered}
$$

\subsection{Estimation Approach}

The above equations illustrate that households' decisions on forestland transfers and off-farm employment are jointly determined. This feature implies that there exists potential interdependence across the disturbances of respective equations. In this case, employing a univariate model to each equation separately may generate biased parameters [23]. Moreover, the structural form specification 
in Equation (2) requires that one dependent variable be included in other equations as a regressor, which induces a possibility of endogeneity. Furthermore, as shown in Section 2.4 below, a large proportion of the sample households choose not to transfer forestland, which means the dependent variables are censored. Therefore, the simultaneous-equation Tobit model is estimated to account for the potential interdependent, endogenous and censored issues synchronously. In detail, the empirical model corresponding to Equation (2) can be represented by:

$$
\begin{gathered}
A_{i n, i}^{*}=\theta_{1} L_{O, i}^{*}+\theta_{2} A_{o u t, i}^{*}+\alpha^{\prime} X_{i}+\varepsilon_{i n, i}, A_{\text {in }, i}=\max \left(0, A_{i n, i}^{*}\right) \\
A_{\text {out }, i}^{*}=\theta_{3} L_{O, i}^{*}+\theta_{4} A_{i n, i}^{*}+\beta^{\prime} X_{i}+\varepsilon_{\text {out }, i}, A_{\text {out }, i}=\max \left(0, A_{\text {out }, i}^{*}\right) \\
L_{O, i}^{*}=\theta_{5} A_{i n, i}^{*}+\theta_{6} A_{\text {out }, i}^{*}+\gamma^{\prime} X_{i}+\varepsilon_{O, i}, L_{O, i}=\max \left(0, L_{O, i}^{*}\right)
\end{gathered}
$$

The reduced form of Equation (3) can be written as:

$$
\begin{gathered}
A_{i n, i}^{*}=\phi^{\prime} X_{i}+u_{i n, i}, A_{\text {in }, i}=\max \left(0, A_{i n, i}^{*}\right) \\
A_{o u t, i}^{*}=\tau^{\prime} X_{i}+u_{o u t, i}, A_{\text {out }, i}=\max \left(0, A_{\text {out }, i}^{*}\right) \\
L_{O, i}^{*}=\omega^{\prime} X_{i}+u_{O, i}, L_{O, i}=\max \left(0, L_{O, i}^{*}\right)
\end{gathered}
$$

where the superscript asteroid represents the unobservable latent variables. $X$ is a vector of exogenous variables, which includes a constant term and those listed in Equation (2). $\varepsilon_{i n, i}, \varepsilon_{\text {out }, i}$ and $\varepsilon_{O, i}$ are random disturbances that follow a multivariate normal distribution $\operatorname{MVN}(0, \Omega)$, where $\Omega$ is the covariance matrix with the correlation coefficients (vector $\rho$ ), between the error terms of the three structural equations. The analogous definitions are applicable on $u_{i n, i}, u_{o u t, i}$ and $u_{O, i}$. The unknown parameters for endogenous variables in the structural form are denoted by $\theta_{1} \sim \theta_{6}$, and the vectors of unknown parameters for exogenous variables in the model are denoted by $\alpha, \beta$, and $\gamma$. The main interests of this study are in the estimated values of $\theta^{\prime} s$.

To obtain consistent estimates of the structural parameters, a two-stage simultaneous-equation procedure, which is proposed by Nelson and Olson [24], is employed. The first stage is to regress the reduced form equations (Equation (4) in this paper), and use the coefficient estimates of $\phi, \tau$, and $\omega$ to generate the predicted values of latent dependent variables. At the second stage, the predicted values of the latent variables are used as instruments on the right-hand sides of the structural form equations (Equation (3) in this paper). Then, a Tobit approach can be applied to estimate the structural parameters. The underlying rationale is that the created instruments are "at least asymptotically uncorrelated with disturbance terms" [24], because only exogenous variables are included in the reduced form equations.

In practice, Nelson and Olson [24] applied the univariate Tobit method to estimate the reduced form and the structural form equations with the predicted values of the endogenous latent variables, from the first stage estimation of the reduced form. Thus, they neglected the possible joint interdependence among different equations. This study employs a multivariate Tobit estimator, embedded in the Nelson-Olson two-stage procedure, to test whether the multivariate setup is more appropriate. The test is based on a fact that the univariate model is a special case of the multivariate one, in the sense that the correlation coefficients $\rho$ between the error terms of the simultaneous equations are constrained to be zero [18]. Therefore, a $z$-test or likelihood ratio $(L R)$ test can be conducted on the multivariate regression with the null hypothesis of $\rho=0$. If the corresponding statistics reject the null hypothesis, then a multivariate Tobit estimator should be performed with the Nelson-Olson procedure to attain more efficient estimates. Otherwise, the univariate model should be selected to separately estimate each equation [25]. In this paper, the multivariate Tobit model is estimated by the maximum simulated likelihood method, in order to avoid the complexity of high dimensional integrals [17]. Moreover, the Geweke-Hajivassiliou-Keane simulator is used, and Halton sequences are employed, to generate the multivariate normal random draws to reduce the computational burden [26]. 


\subsection{Data Source}

The data was collected from an SFA-conducted, three-wave household survey. The information was collected using face-to-face interviews and a structured questionnaire. The questionnaire involved information on demographics, income, forestry production, off-farm employment activity and forestland transfer participation. The first-wave survey was carried out in 2010, and obtained the information of 2003 (pre-CFTR) and 2007-2009 (post-CFTR). The second and the third waves were performed in 2012 and 2014, respectively, and collected the information from 2010 to 2013. Nine provinces were selected, since they are the representatives of China's major collective forest regions. As depicted in Figure 1, the Liaoning province and the Sichuan province are in the northeast and southwest forest regions, respectively. The Shandong and Henan provinces are the behalves of the central forest region, while the remaining five provinces are in the southern forest region. The sample's geographical distribution means that our data can reflect the diversified characteristics of China's collective forest regions (For instance, among these nine provinces, the forest cover is between 16.7\% and $66.0 \%$, and the area ratio of collective-owned forestland to total forestland is between $30 \%$ and 92\% [27]. Regarding the economic development, the annual disposable income of rural household per capita ranged from 1519.91 to 3391.72 USD (100 USD = 622.84 Yuan) in 2015 [28]).

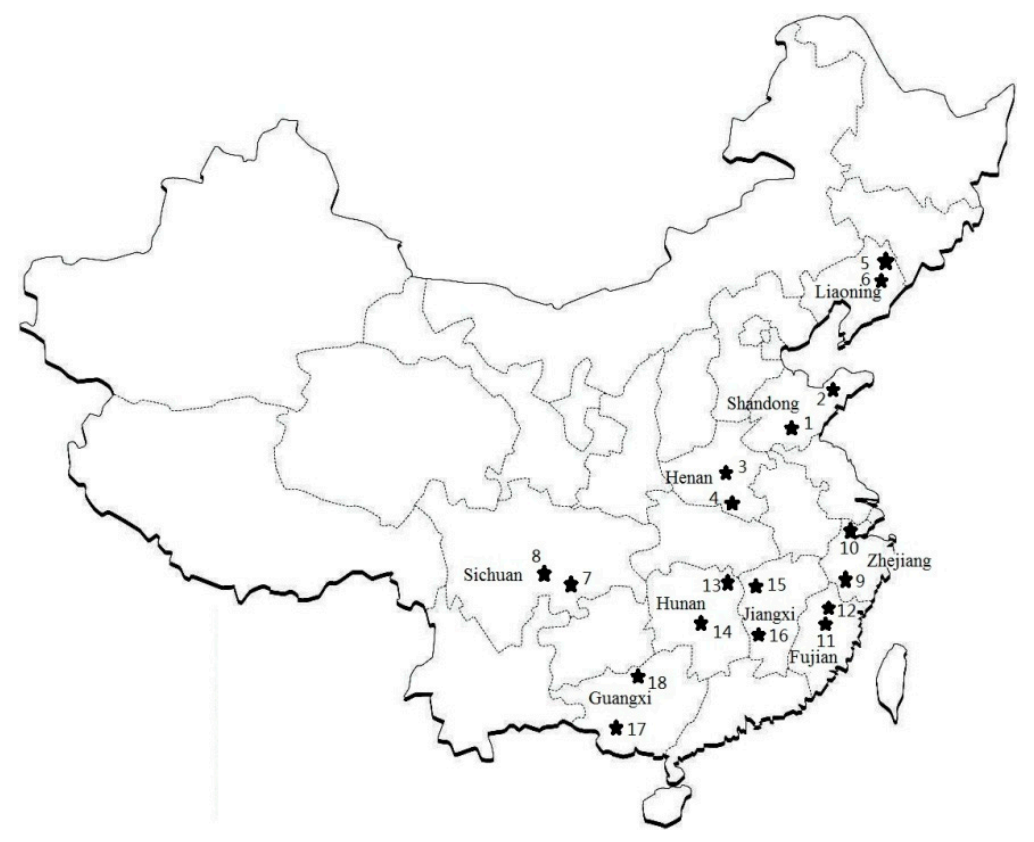

Figure 1. Spatial distribution of sample area. Note: Counties 1-18 are Mengyin, Laizhou, Wuyang, Shihe, Qingyuan, Benxi, Weiyuan, Danleng, Suichang, Deqing, Shunchang, Shaxian, Pingjiang, Hongjiang, Tonggu, Suichuan, Pingguo, and Huanjiang, respectively.

For each province, a stratified random sampling technique was adopted and two counties were selected [29]. Then, three towns were randomly selected from these counties. Within each town, three villages were randomly chosen, and around 10-15 farmers were investigated in each village. We merged the three-wave surveys into a large dataset. Those with incomplete records or inconsistent information in the questionnaire were dropped. Finally, the sample that was used in this study was comprised of 1497 households, each of whom had 8 observations in 2003, and from 2007 to 2013.

\subsection{Descriptive Statistics}

Table 1 illustrates that China's forestland rental market is at an immature stage. Our sample showed that by 2013 , only $5.48 \%(82 / 1497)$ and $2.74 \%(41 / 1497)$ of households had transferred in 
and out their forestland, far behind that of farmland transfers. For the households with positive observations on forestland transfers, the average rent-in area was $79.52 \mathrm{mu}(1 \mathrm{mu}=1 / 15$ hectare), which is around 3.7 times that of the average rent-out area. The big difference reflects a specific mentality associated with Chinese peasants. That is, the land is usually deemed as the "lifeblood" for rural families [11], hence households tend to be very cautious on their forestland asset, and would not transfer them out rashly. Off-farm employment is measured in the data by the ratio of off-farm income to household total income. Generally, the efforts engaged in off-farm activities and forestland management can be reckoned as substitutes. Therefore, the off-farm employment is expected to impose negative and positive effects on rent-in and rent-out, respectively. Of the whole sample, nearly half of household income is from off-farm activities (see Table 1). It is worth noting that the rate is up to $60.36 \%$ for the rent-out households, and is significantly higher than that of autarkic households at the $5 \%$ statistical level. This provides preliminary evidence that households with more off-farm employment are more likely to transfer out their forestland.

Table 1. Descriptive statistics of variables used in regression.

\begin{tabular}{|c|c|c|c|c|c|}
\hline & \multirow{2}{*}{ Unit } & \multirow{2}{*}{ Full Sample } & \multicolumn{3}{|c|}{ Sub-Sample by Household Type } \\
\hline & & & Rent-In & Autarky & Rent-Out \\
\hline \multicolumn{6}{|l|}{ Endogenous variables } \\
\hline Rent-in area & $\mathrm{mu}$ & $0.54(13.47)$ & $79.52(143.02)$ & N.A. & N.A. \\
\hline Rent-out area & $\mathrm{mu}$ & $0.07(2.57)$ & N.A. & N.A. & $21.50(38.70)$ \\
\hline Off-farm employment & $\%$ & $49.80(34.13)$ & $48.69(34.65)$ & $49.77(34.12)$ & $60.36(37.07)^{* *}$ \\
\hline \multicolumn{6}{|l|}{ Exogenous variables } \\
\hline \multicolumn{6}{|l|}{ Market variables } \\
\hline Transaction cost & / & $0.22(0.86)$ & $0.05(0.09)^{* * *}$ & $0.23(0.87)$ & $0.06(0.05)^{* * *}$ \\
\hline Timber price & Yuan $/ \mathrm{m}^{3}$ & $427.06(97.24)$ & $476.02(97.16)$ & $426.65(97.17)$ & $448.08(92.35) *$ \\
\hline Wage rate & Yuan/day & $48.97(19.42)$ & $49.63(13.75)$ & $48.92(19.44)$ & $60.91(21.31)^{* * *}$ \\
\hline \multicolumn{6}{|l|}{ Forestland attributes } \\
\hline Foreland area & & $34.91(66.76)$ & $36.21(45.69)^{* * *}$ & $34.82(66.84)$ & $59.35(74.56)^{* * *}$ \\
\hline Area per plot & $\mathrm{mu} / \mathrm{plot}$ & $12.28(21.73)$ & $10.19(10.23)$ & $12.27(21.79)$ & $18.63(22.12)^{* * *}$ \\
\hline \multicolumn{6}{|l|}{ Household attributes } \\
\hline Age & Years & $51.08(10.91)$ & $45.88(9.46)^{* * *}$ & $51.11(10.91)$ & $52.00(12.86)$ \\
\hline Education & Years & $7.35(2.76)$ & $8.41(2.56)^{* * *}$ & $7.35(2.76)$ & $6.85(2.97)$ \\
\hline Leadership & $0 / 1$ & $0.25(0.43)$ & $0.35(0.48) * *$ & $0.25(0.43)$ & $0.34(0.48)$ \\
\hline \multirow{2}{*}{ Household income } & Thousand & 23.18 & $30.74^{* *}$ & 23.11 & $28.70^{* *}$ \\
\hline & Yuan/year & $(30.86)$ & $(36.05)$ & (30.83) & $(28.02)$ \\
\hline Household size & Persons & $3.98(1.47)$ & $4.20(1.32)$ & $3.98(1.47)$ & $3.78(1.49)$ \\
\hline \multicolumn{6}{|l|}{ Village attributes } \\
\hline Mountain & $0 / 1$ & $0.56(0.50)$ & $0.60(0.49)$ & $0.56(0.50)$ & $0.46(0.50)$ \\
\hline Road & $0 / 1$ & $0.72(0.45)$ & $0.55(0.50)^{* * *}$ & $0.72(0.45)$ & $0.85(0.36)$ * \\
\hline County distance & $\mathrm{km}$ & $35.14(30.83)$ & $34.94(30.24)$ & $35.17(30.82)$ & $28.62(33.54) * *$ \\
\hline Observations & / & 11,976 & 82 & 11,853 & 41 \\
\hline
\end{tabular}

Note: All price indexes have been deflated by the locally rural consumer price index $(1994=100)$. Area per plot is calculated based on the forestland area before transfer. The standard deviation is reported in parentheses. Taking the autarky group as the benchmark, the Wilcoxon rank-sum test is performed to compare the sample mean between different subgroups. ${ }^{*}, * *$ and ${ }^{* * *}$ denote a statistical significance at the $10 \%, 5 \%$ and $1 \%$ levels, respectively $[7,9]$. N.A. means not applicable. The transaction cost is denoted by an index, hence the unit is not reported.

Equation (1) indicates the exogenous variables that potentially affect forestland transfer decisions, as listed in Table 1. For transaction cost $(T C)$, the inverse of village-average forestland area per household, proposed by Kimura et al. [30], is used as a proxy, and the coefficient is expected to be negative [31] (The rationale is intuitive: Given a certain amount of forestland that one desires to transfer, if the average forestland area per household within that village is smaller, then more households would be involved in transactions, hence the search and negotiation costs are higher [29]. It can be found that a higher village-average land size per household indicates a lower transaction cost. To make them logically consistent while keeping the magnitude of the estimated coefficient unchanged, we take an inverse and logarithm operation on the index, i.e., $\ln (1 / x)=-\ln x$.). The timber price $(p)$ and wage rate $(w)$ are measured by the average level in local counties. The forestland $(\bar{A})$ endowment variable is represented by the forestland area before transfer. Unluckily, no efficient information was collected on the forestland rent fee ( $r$. . As Jin and Deininger [32] argue, the land rent is a function of the local wage 
rate, transaction cost and land endowment, etc. Given these factors have been included in our model, the rent fee should not be added again to avoid multicollinearity.

Vector $Z$ consists of the household and village characteristics, as displayed in Table 1 . The age and the education level refer to the household head. The leadership variable is equal to one if household members hold a cadre position in local government. If the village is in a mountainous region and the roads in that village are paved with asphalt-related materials, then the mountain and road variables are equal to one, respectively. Otherwise, the above three dummy variables are equal to zero. The forestland fragmentation variable is also included in the model since previous literature indicates that it affects production [33]. According to Tan et al. [34], the fragmentation level is indexed by the forestland size per plot. It should be noted that a higher value of the forestland area per plot indicates less fragmented land, while a lower value implies more fragmented land. The county distance variable is denoted by the distance from that village to the closest county. The Wilcoxon rank-sum tests suggest that, compared with the autarky group, both rent-in and rent-out groups present significant differences on numerous covariates. For instance, no matter what the direction of transfer, the transaction cost associated with rented households is significantly lower than that of non-rented households at the $1 \%$ statistical level.

Regarding the rent-in equation, the signs of the estimated coefficients of timber price, household member size, household income, forestland area per plot, mountain, and distance to the closest county are expected to be positive. The coefficients of wage rate, forestland area, and road variables are expected to be negative. The signs for other parameters are ambiguous. Due to the mirror image phenomenon [7], the coefficient signs are anticipated to be reversed for the rent-out equation. For the rotation period variable $(T)$, the tree species within the same county should be similar. Hence, the county dummies are introduced to denote the rotation period variable. Another benefit of introducing these county dummies is that the unobservable heterogeneity can be captured by the regional dummies, at least to some extent [9]. Considering the sample ranged from 2003 to 2013, the year dummies are also included in the model, to capture the unobservable year-specific effects. In practice, the Huber-White robust estimator of variance is calculated for appropriate inference [35].

\section{Results and Discussion}

\subsection{Model Specification Tests}

To make the structural equations identifiable, following Feng and Heerink [8], labor size (able-bodied, between 16 and 65 years old) and household member size were introduced into the off-farm employment equations and into the forest land transfer equations, respectively, as proxies for a theoretical labor endowment variable $(\bar{L})$. Furthermore, two fragmentation indices, denoted by the area per plot, were calculated based on the area before and after rent. These were taken into the forestland transfer equations and the off-farm employment equations, respectively. The quadratic term of forestland area was only included in the rent-in equation, not in the other two equations. Therefore, in each equation, there were at least two exogenous variables absent from the other two equations. Thus, the structural equations were identified [36].

As indicated in Table 2, the multivariate Tobit specification is tested against the univariate specification. In the trivariate case, the $L R$ joint test of $\rho$ cannot reject the null hypothesis that the correlations across different equations are all equal to zero, both in the reduced and structural form equations. This implies that Equation (3) does not need to be estimated in a systematic fashion. However, as an alternative, the $z$ test suggests the $\rho_{13}$ is statistically different from zero at the $5 \%$ significant level, both in the reduced and structural form equations. Therefore, we further investigate the cross-equation correlations in a bivariate-equation Tobit model, i.e., combine rent-in equation and rent-out equation with off-farm employment equation, respectively. Table 2 shows that both $z$ test and $L R$ test cannot reject the null hypothesis that $\rho_{13}=0\left(\rho_{23}=0\right)$ for rent-in (rent-out) in the bivariate case. The trivariate and bivariate tests defensibly illustrate the across-equation interdependencies are not a 
serious problem for the data used in this paper, and the univariate Tobit approach is more appropriate to estimate the system of Equation (3), as Nelson and Olson [24] proposed. Hereafter, the discussion is based on the traditional Nelson-Olson two-stage procedure, where the three equations in Equation (3) are estimated separately.

Table 2. Cross-equation correlations tests.

\begin{tabular}{ccccccc}
\hline & \multicolumn{2}{c}{ Reduced Form Equations } & \multicolumn{2}{c}{ Structural Form Equations } \\
\cline { 2 - 6 } & Trivariate & $\begin{array}{c}\text { Ren-In } \\
\text { Bivariate }\end{array}$ & $\begin{array}{c}\text { Rent-Out } \\
\text { Bivariate }\end{array}$ & Trivariate & $\begin{array}{c}\text { Ren-In } \\
\text { Bivariate }\end{array}$ & $\begin{array}{c}\text { Rent-Out } \\
\text { Bivariate }\end{array}$ \\
\hline$\rho_{12}$ & $-0.37(0.32)$ & & & $-0.42(0.44)$ & \\
$\rho_{13}$ & $-0.07(0.03)$ & $-0.06(0.05)$ & & $-0.07(0.03)$ & $-0.07(0.05)$ & \\
$\rho_{23}$ & $0(0.04)$ & & $0.01(0.07)$ & $0.01(0.04)$ & & $0.02(0.07)$ \\
& $-1.15<0.25>$ & & & $-0.96<0.34>$ & \\
$z$ test & $-1.99<0.05>* *$ & $-1.37<0.17>$ & & $-2.24<0.03>* *$ & $-1.55<0.12>$ & \\
& $0.1<0.92>$ & & $0.19<0.85>$ & $0.35<0.73>$ & & $0.33<0.74>$ \\
$L R$ test & $4.26<0.24>$ & $2.01<0.16>$ & $0.04<0.84>$ & $5.02<0.17>$ & $2.51<0.11>$ & $0.13<0.72>$ \\
\hline
\end{tabular}

Note: The subscript 1, 2, and 3 denote equations of rent-in, rent-out, and off-farm employment, respectively. The $p$-value and the Huber-White robust standard error is reported in angle brackets and in parentheses, respectively. For trivariate model, the $L R$ test is a joint test of $\rho_{12}=\rho_{13}=\rho_{23}=0 .{ }^{* *}$ indicates statistical significance at the $5 \%$ level.

\subsection{Determinants of Forestland Rent-In}

The Nelson-Olson estimates of Equation (3) are reported in Table 3, and the associated average partial effects (APE) are displayed in Table 4 (As stated in Section 2.2, in the first stage of the Nelson-Olson procedure, the reduced form system (Equation (4)) is estimated to generate the instruments of endogenous variables. For the sake of brevity, the estimation results of Equation (4) are not reported here, but are available from the authors upon requests). As expected, the effect of off-farm employment on forestland rent-in is negative, and significant at the $5 \%$ statistical level. That is, more off-farm employment is associated with less forestland rent-in. Moreover, the APE shows that a $1 \%$ increase in off-farm income rate would induce a decrease of forestland rent-in by $1.04 \mathrm{mu}$. As Section 2.1 argues, more off-farm employment restricts the availability of labor in forestland cultivation, hence lowering the propensity to transfer-in forestland. This is particularly the case for China, where the large rural-urban income disparity, and the remarkable earning gap between agricultural and industrial sectors, render off-farm employment and migration attractive $[37,38]$. The preference for off-farm work can be justified by the fact that, of the whole sample, the off-farm income accounted for half of household total income (Table 1), and presents a trend with an increase from $43.60 \%$ in 2003 to $55.76 \%$ in 2013. This phenomenon partially explains why the majority of households have not transferred in more forestland. 
Table 3. Estimation results of the simultaneous-equation Tobit model.

\begin{tabular}{cccc}
\hline & Rent-In & Rent-Out & Off-Farm Employment \\
\hline Rent-in & & $-0.05(0.00)^{* * *}$ & $-0.01(0.00)^{* * *}$ \\
Rent-out & $-2.52 \times 10^{-4}\left(1.61 \times 10^{-4}\right)$ & & $0.01(0.01)^{* * *}$ \\
Off-farm employment & $-14.78(6.45)^{* *}$ & $-0.01(0.06)$ & \\
Transaction cost & $-67.81(21.64)^{* * *}$ & $-11.36(1.04)^{* * *}$ & $0.34(0.46)$ \\
Timber price & $0.59(0.22)^{* * *}$ & $-0.12(0.01)^{* * *}$ & $0.02(0.01)^{* * *}$ \\
Wage rate & $0.48(2.46)$ & $0.38(0.05)^{* * *}$ & $0.24(0.05)^{* * *}$ \\
Foreland area & $-1.36(0.58)^{* *}$ & $0.12(0.02)^{* * *}$ & $-0.04(0.01)^{* * *}$ \\
Forestland area square & $-8.12 \times 10^{-4}\left(2.26 \times 10^{-3}\right)$ & & \\
Area per plot & $1.12(0.47)^{* *}$ & $-0.99(0.11)^{* * *}$ & $-0.01(0.03)$ \\
Age & $-6.68(8.14)$ & $-5.38(0.07)^{* * *}$ & $-0.43(0.25)^{*}$ \\
Age square & $0.01(0.08)$ & $0.05(0.00)^{* * *}$ & $0.00(0.00)^{* *}$ \\
Education & $11.27(5.45)^{* *}$ & $-1.72(0.41)^{* * *}$ & $0.57(0.15)^{* * *}$ \\
Leadership & $33.56(25.75)$ & $12.89(2.51)^{* * *}$ & $0.46(0.84)$ \\
Household income & $1.21(0.47)^{* * *}$ & $-0.02(0.04)$ & $0.07(0.02)^{* * *}$ \\
Household size & $27.71(10.95)^{* *}$ & $-3.92(0.79)^{* * *}$ & $2.21(0.32)^{* * *}$ \\
Mountain & $-67.24(43.15)$ & $-9.53(2.90)^{* * *}$ & $-5.10(0.89)^{* * *}$ \\
Road & $-74.58(29.31)^{* *}$ & $15.46(3.36)^{* * *}$ & $-1.38(1.09)$ \\
County distance & $-0.66(0.48)$ & $0.03(0.05)$ & $-0.01(0.01)$ \\
Constant & $-431.10(282.99)$ & $-410.12(3.73)^{* * *}$ & $30.97(6.84)^{* * * *}$ \\
Joint F test of county dummies & 0.90 & $2584.54^{* * *}$ & $65.722^{* * *}$ \\
Joint F test of year dummies & 1.22 & $118.93 * * *$ & $9.85^{* * *}$ \\
Uncensored/Censored number & $82 / 11,894$ & $41 / 11,935$ & $9967 / 2009$ \\
\hline
\end{tabular}

Note: The Huber-White robust standard error is reported in parentheses. ${ }^{*},{ }^{* *}$ and ${ }^{* * *}$ denote a statistical significance at the $10 \%, 5 \%$ and $1 \%$ levels, respectively $[7,9]$. Year and county dummies are included. For the sake of brevity, their coefficients are not reported, but are available upon request to authors.

In line with theoretical expectation, Tables 3 and 4 illustrate that transaction cost has a negative effect on forestland rent-in, and is significant at the $1 \%$ statistical level. The magnitude of its marginal effect (-4.77) highlights the crucial role of transaction cost in farmers' rent-in decisions. Similarly, forestland area before transfer, and road conditions in the local village, also impose a negative effect on rent-in, both of which are significant at the $5 \%$ risk level. For forestland area, the negative sign suggests that the direction of forestland transactions is from households with larger forestland endowments to those with smaller ones, i.e., the rental market tends to equalize cultivated forestland and balance the disparities among households [39]. Through transfer, the amount of forestland available to land-poor households will increase. These findings suggest that the land lease market can reach the same results as the administrative reallocation does, at least as far as equity is concerned, and strongly supports a so-called factor equalization effect [32]. To further examine the existence of economies of scale, the squared term of forestland area is introduced. The coefficient is not statistically significantly different from zero, which implies households' behavior of forestland rent-in is unlikely due to the motivation of economies of scale. Good road and transportation conditions in local regions could facilitate villagers to travel outside and seek off-farm employment opportunities $[40,41]$, thus playing a negative role in households' decision on forestland rent-in. Furthermore, as discussed in Section 2.4, a lower value of the average plot size indicates more fragmented forestland. Therefore, the positive sign of average plot size indicates that forestland fragmentation has a negative effect on forestland rent-in. The underlying reason may be that fragmentation increases production costs, hampers technical efficiency, thereby diminishing the profitability of land cultivation $[33,34]$. 
Table 4. Average partial effects based on expected values of truncated outcomes.

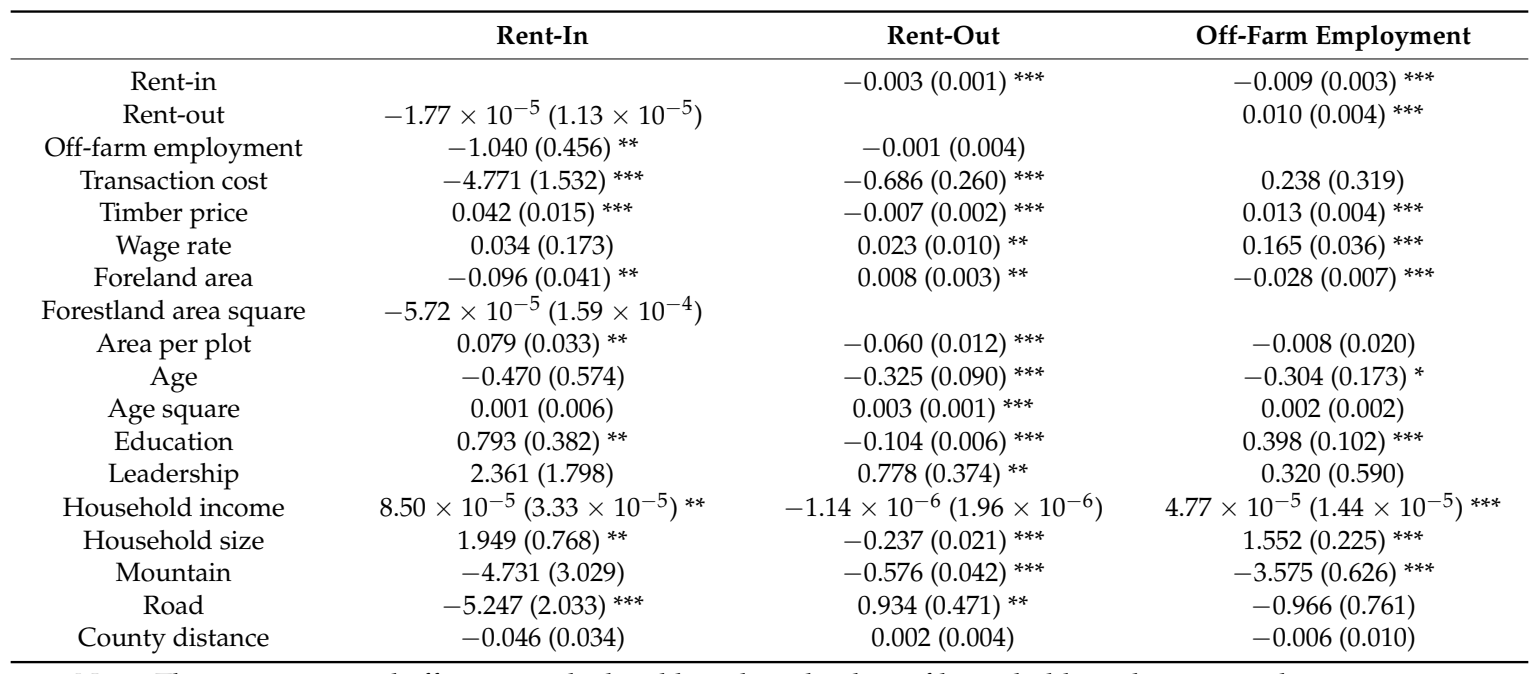

Note: The average partial effects are calculated based on the data of households with positive observations on dependent variables. The standard error is reported in parentheses. ${ }^{*}, * *$ and ${ }^{* * *}$ denote a statistical significance at the $10 \%, 5 \%$ and $1 \%$ levels, respectively $[7,9]$.

Contrary to the above-mentioned negative effects, Tables 3 and 4 also illustrate the factors that would promote forestland rent-in. For instance, the positive and statistically significant coefficient for timber price suggests that the demand for rental land is likely to be higher when the timber price increases, because of a higher rate of return on forestland investment. Likewise, the household size also has a positive effect, and is significant at the $1 \%$ risk level. The positive sign indicates that forestland is being transferred from households with fewer family members to the ones with more members. Combined with the above-mentioned forestland area effect, it can be found that the rental market is moving forestland from those with less labor and more land to those with more labor and less land, a result that is in line with Huang et al. [9], regarding China's farmland rental market. This phenomenon illustrates that the discrepancy of the labor-forestland ratio among households can be reduced, and further implies that the forestland rental market is likely to improve the efficiency of factor allocation, at least to some extent. The positive and statistically significant coefficients of education and income variables are consistent with our theoretical anticipations.

\subsection{Determinants of Forestland Rent-Out}

A surprising finding is that off-farm employment had no statistically significant effect on forestland rent-out, which is inconsistent with the theoretical expectation. This result indicates that there might be other reasons that influence households' rent-out decisions, and restrict the role of off-farm employment. One plausible reason is associated with the social security function of land. In Chinese history, the land is usually deemed as a "lifeline" or "lifeblood" by peasants and performs a pivotal function as a social safety net in peasants' livelihoods [11,42]. Currently, temporality is an important feature of rural-urban migration flow in China, partly because the existing household registration system hinders rural peasants to settle down permanently in cities [43]. Given the institutional constraints, peasants who undertake off-farm work are expelled from the urban social security system. Thus, they must enroll in the rural social security services at their local villages, which is widely considered as an unsound system [44]. Therefore, households are inclined to hold their forestland, and use it as a means of livelihood insurance to respond to the jeopardy of losing jobs. This motivation neutralizes the positive effect of off-farm employment on rent-out, leading to a statistically insignificant coefficient.

At the same time, the forestland rent-out behavior is found to be negatively affected by that of rent-in, which is significant at the $1 \%$ risk level. The sign is consistent with our expectation, 
since, theoretically, households will not transfer in and out at the same time [30]. As anticipated, the transaction cost variable has a negative effect on rent-out, with a significance at the $1 \%$ risk level. It is noteworthy that the same argument is also found for the estimation of rent-in behavior. Among other variables, an intriguing mirror-image phenomenon is observed [7], i.e., the signs are reversed between rent-in and rent-out estimation. These mirror-image and statistically significant variables involve timber price, forestland area, fragmentation, education, household size, and road condition. The mirror-image phenomenon results from the fact that rent-in and rent-out are two opposite sides of the transfer action. Thus, the underlying rationale explaining the rent-in decisions can also be applied to interpret the rent-out decisions. Therefore, we do not continue to explain the rationale of the estimated signs of these mirror-image variables, as they have been discussed above in the rent-in case (Section 3.2).

It should be noted that there are several variables in which the status of statistical significance is changed between the rent-in and the rent-out estimations. For instance, the coefficients of wage, age, leadership, and mountain are not significantly different from zero in the rent-in equation, but they indeed refuse the null hypotheses in the rent-out case, at the $5 \%$ or $1 \%$ risk level. By contrast, household income has a significant effect on the rent-in activity, but not on the rent-out behavior. These findings indicate that the forestland rent-in and rent-out decisions are somehow distinct and asymmetric [9]. These asymmetric variables are basically consistent with theoretical expectations. For example, an increase of wage rate makes the opportunity cost of forestland management become higher, hence, imposing a positive effect on forestland rent-out. For the leadership variable, cadres are usually the capable persons in local communities in rural China and are endowed with more social capital and wider social networks. With these social connections, for households with cadre members, it is relatively easier to find and obtain off-farm opportunities [45], thus they prefer leasing out forestland. A significant $U$-shaped relationship is found between household age and forestland rent-out, which suggests that households with younger and elder heads are more likely to rent out forestland. The intuitions underlying these two groups are distinctive. The younger household heads are inclined to undertake off-farm employment [46], while elder ones lease out their forestland, probably due to physical unaffordability to cultivate it. The turning point in the effect of age is around 54 years.

\subsection{Determinants of Off-Farm Employment}

Given that off-farm employment significantly influences rent-in behavior, we are also interested in the factors that determine households' decisions about off-farm employment. In line with theoretical expectations, wage rate had a positive effect on off-farm employment decisions and is significant at the $1 \%$ statistical level. The comparison of the numerical size of coefficients in Table 4 highlights that wage rate is a crucial determinant, as well as household member size. Another important factor refers to the education of the household head, which is significant at the $1 \%$ statistical level. The positive sign suggests that well-educated farmers have advantages to obtain more off-farm work opportunities. The magnitudes of coefficients also illustrate that the mountain variable is a critical factor that negatively affects the off-farm behavior at the $1 \%$ significance level. Other things being equal, the ratio of off-farm income to total income in the mountainous regions is $3.58 \%$ lower than that of the plain regions, based on the estimated coefficient. The life-cycle effect is not supported empirically, and the significantly negative sign of age suggests that the younger farmers are more inclined to engage in the off-farm sector. Other significant variables are basically consistent with theoretical anticipations. It is worth noting that both rent-in and rent-out significantly influence off-farm employment at the $1 \%$ significance level. As expected, rent-in forestland would decrease the possibility to work in the off-farm sector, while rent-out would stimulate this likelihood. 


\section{Conclusions}

Drawing upon a nationally representative household survey, this paper investigated the effect of off-farm employment on forestland transfer decisions. With a framework of households' optimal decisions on labor and forestland allocation, there exists a bi-directional causality between off-farm employment and forestland transfers. This brings about the issues of potential endogeneity and possible interdependence. Moreover, the fact that the majority of households in our sample did not transfer their forestland means that we are dealing with a problem of a censored dependent variable. Hence, a simultaneous-equation Tobit model was needed to account for endogeneity, interdependency and censoring. The Nelson-Olson two-stage estimates showed that households' forestland rent-in decisions were negatively affected by off-farm employment, and that the effect was significant at the $5 \%$ statistical level. The magnitude of APE (-1.04) suggests that off-farm employment is a crucial factor that impedes the expansion in demand of the forestland rental market.

A policy-oriented dilemma can be derived from this finding. That is, urban-rural integration or urbanization has become a nationwide strategy following the release of "The National New-Type Urbanization Plan (2014-2020)" by the Chinese Central Government (http:/ /www.gov.cn/zhengce/ 2014-03/16/content_2640075.htm.). In this strategy, off-farm employment and migration are highly encouraged and supported by governments, thus indicating a rise in off-farm income rate. Based on our finding, this trend would reduce the amount of rent-in, which implies the forestland rental market might remain, or become more, inactive in future. Therefore, the Chinese government encounters a dilemma between the development of the rural-urban economy and the establishment of the forestland rental market. The policymakers should-when dealing with the rural excessive labor issue through the New-Type Urbanization strategy—also pay much attention to the rural land issue. The efforts to resolve rural labor problems may impose an extra and unexpected cost on the rural land problem. Both labor and land are fundamental endowments for rural households, thus policy interventions aimed at either of the two aspects should be based on the cost-benefit analysis of both. For the following second stage of the CFTR, how to balance the above-mentioned dilemma is a big challenge for policymakers.

We found that off-farm work has no significant effect on rent-out. This unexpected result might be caused by China's specific conditions. In urban China, migrants cannot enroll in the urban social security system due to a restriction of the household registration system. In rural China, the social security system is relatively weak and incomplete. Under these circumstances, although households engage in the industrial sector, they are still inclined to hold their forestland as a means of social security to avoid the risk of unemployment. Therefore, to stimulate households to transfer out their forestland, the governments should pay more attention to adjusting the household registration system and improve the rural social security services. Besides off-farm employment, we find the transaction cost is a crucial obstacle to the development of the forestland rental market, regardless of the rent-in or rent-out behaviors. This conclusion reflects that, currently, the transaction cost during forestland transfers might still be high, even though the first stage of the CFTR is concluding. For policymakers, how to reduce the transaction cost of forestland transfers should be one of the main concerns in the second stage of the CFTR. An outstanding finding is that forestland is being transferred from households with less labor and more forestland, to those with more labor and less forestland. This factor equalization effect indicates that forestland transfers might be a feasible way to achieve the dual goals of equity and efficiency. Therefore, supportive policies to facilitate the functioning of the forestland rental market should be put forward in the following steps of the CFTR.

Acknowledgments: This study was supported by the National Natural Science Foundation of China (No. 71403213), the Humanities and Social Science Project of Ministry of Education (No. 14YJC790166), and the China Postdoctoral Science Foundation (No. 2015T80196, No. 2014M550974).

Author Contributions: Han Zhang, Can Liu and Jari Kuuluvainen conceived and designed this study; Hongqiang Yang and Yi Xie performed the experiments including collecting the materials; Jari Kuuluvainen and Han Zhang contributed to data analysis; Han Zhang, Jari Kuuluvainen and Can Liu wrote the paper.

Conflicts of Interest: The authors declare no conflict of interest. 


\section{References}

1. Lin, J.Y. Rural reforms and agricultural growth in China. Am. Econ. Rev. 1992, 82, 34-51.

2. Liu, C.; Liu, H.; Wang, S. Has China's new round of collective forest reforms caused an increase in the use of productive forest inputs? Land Use Policy 2017, 64, 492-510. [CrossRef]

3. Yin, R.; Yao, S.; Huo, X. China's forest tenure reform and institutional change in the new century: What has been implemented and what remains to be pursued? Land Use Policy 2013, 30, 825-833. [CrossRef]

4. Xie, L.; Berck, P.; Xu, J. The effect on forestation of the collective forest tenure reform in China. China Econ. Rev. 2016, 38, 116-129. [CrossRef]

5. Liu, P.; Yin, R.; Li, H. China's forest tenure reform and institutional change at a crossroads. For. Policy Econ. 2016, 72, 92-98. [CrossRef]

6. Chen, R.; Ye, C.; Cai, Y.; Xing, X.; Chen, Q. The impact of rural out-migration on land use transition in China: Past, present and trend. Land Use Policy 2014, 40, 101-110. [CrossRef]

7. Deininger, K.; Jin, S. The potential of land rental markets in the process of economic development: Evidence from China. J. Dev. Econ. 2005, 78, 241-270. [CrossRef]

8. Feng, S.; Heerink, N. Are farm households' land renting and migration decisions inter-related in rural China? NJAS Wagening. J. Life Sci. 2008, 55, 345-362. [CrossRef]

9. Huang, J.; Gao, L.; Rozelle, S. The effect of off-farm employment on the decisions of households to rent out and rent in cultivated land in China. China Agric. Econ. Rev. 2012, 4, 5-17. [CrossRef]

10. Kung, J.K.-S. Off-Farm labor markets and the emergence of land rental markets in rural China. J. Comp. Econ. 2002, 30, 395-414. [CrossRef]

11. Xie, Y.; Jiang, Q. Land arrangements for rural-urban migrant workers in China: Findings from Jiangsu Province. Land Use Policy 2016, 50, 262-267. [CrossRef]

12. Yao, Y. The development of the land lease market in rural China. Land Econ. 2000, 76, 252-266. [CrossRef]

13. Dong, X.-Y. Two-tier land tenure system and sustained economic growth in post-1978 rural China. World Dev. 1996, 24, 915-928. [CrossRef]

14. Xu, X.; Zhang, Y.; Li, L.; Yang, S. Markets for forestland use rights: A case study in Southern China. Land Use Policy 2013, 30, 560-569. [CrossRef]

15. Siikamäki, J.; Ji, Y.; Xu, J. Post-reform forestland markets in China. Land Econ. 2015, 91, 211-234. [CrossRef]

16. Amemiya, T. Multivariate Regression and Simultaneous Equation Models when the Dependent Variables Are Truncated Normal. Econometrica 1974, 42, 999-1012. [CrossRef]

17. Lee, L.-F. Multivariate tobit models in econometrics. In Handbook of Statistics; Maddala, G.S., Rao, C.R., Vinod, H.D., Eds.; North-Holland: Amsterdam, The Netherlands, 1993; Volume 11, pp. 145-173.

18. Yoo, S.-H. Analysing household bottled water and water purifier expenditures: Simultaneous equation bivariate Tobit model. Appl. Econ. Lett. 2005, 12, 297-301. [CrossRef]

19. Roodman, D. Fitting fully observed recursive mixed-process models with cmp. Stata J. 2011, 11, 159-206.

20. Bowlus, A.J.; Sicular, T. Moving toward markets? Labor allocation in rural China. J. Dev. Econ. 2003, 71, 561-583. [CrossRef]

21. Favada, I.M.; Kuuluvainen, J.; Uusivuori, J. Consistent estimation of long-run nonindustrial private forest owner timber supply using micro data. Can. J. For. Res. 2007, 37, 1485-1494. [CrossRef]

22. Heaps, T. Convergence of optimal harvesting policies to a normal forest. J. Econ. Dyn. Control 2015, 54, 74-85. [CrossRef]

23. Wooldridge, J.M. Econometric Analysis of Cross Section and Panel Data, 2nd ed.; MIT Press: Cambridge, MA, USA, 2010.

24. Nelson, F.; Olson, L. Specification and Estimation of a Simultaneous-Equation Model with Limited Dependent Variables. Int. Econ. Rev. 1978, 19, 695-709. [CrossRef]

25. Kuhlgatz, C.; Abdulai, A.; Barrett, C.B. Food aid allocation policies: Coordination and responsiveness to recipient country needs. Agric. Econ. 2010, 41, 319-327. [CrossRef]

26. Train, K. Discrete Choice Methods with Simulation, 2nd ed.; Cambridge University Press: New York, NY, USA, 2009.

27. State Forestry Administration of China (SFA). China Forest Resource Report (2009-2013); China Forestry Publishing House: Beijing, China, 2014. 
28. National Bureau of Statistics of China (NBSC). National Bureau of Statistics of China Database. Available online: http:/ / www.stats.gov.cn/ (accessed on 10 May 2017).

29. Liu, C.; Wang, S.; Liu, H. An Examination of the Effects of Recent Tenure Reforms in China's Collective Forests on Peasants' Forest Activities and their Income. Int. For. Rev. 2017, 19, 55-67. [CrossRef]

30. Kimura, S.; Otsuka, K.; Sonobe, T.; Rozelle, S. Efficiency of land allocation through tenancy markets: Evidence from China. Econ. Dev. Cult. Chang. 2011, 59, 485-510. [CrossRef]

31. Skoufias, E. Household resources, transaction costs, and adjustment through land tenancy. Land Econ. 1995, 71, 42-56. [CrossRef]

32. Jin, S.; Deininger, K. Land rental markets in the process of rural structural transformation: Productivity and equity impacts from China. J. Comp. Econ. 2009, 37, 629-646. [CrossRef]

33. Manjunatha, A.V.; Anik, A.R.; Speelman, S.; Nuppenau, E.A. Impact of land fragmentation, farm size, land ownership and crop diversity on profit and efficiency of irrigated farms in India. Land Use Policy 2013, 31, 397-405. [CrossRef]

34. Tan, S.; Heerink, N.; Kruseman, G.; Qu, F. Do fragmented landholdings have higher production costs? Evidence from rice farmers in Northeastern Jiangxi province, P.R. China. China Econ. Rev. 2008, 19, 347-358. [CrossRef]

35. Che, Y. Off-farm employments and land rental behavior: Evidence from rural China. China Agric. Econ. Rev. 2016, 8, 37-54. [CrossRef]

36. Maddala, G.S. Limited Dependent and Qualitative Variables in Econometrics; Cambridge University Press: Cambridge, UK, 1983.

37. Sicular, T.; Ximing, Y.; Gustafsson, B.; Shi, L. The Urban-Rural Income Gap and Inequality in China. Rev. Income Wealth 2007, 53, 93-126. [CrossRef]

38. Zhao, Y. Labor Migration and Earnings Differences: The Case of Rural China. Econ. Dev. Cult. Chang. 1999, 47, 767-782. [CrossRef]

39. Holden, S.T.; Otsuka, K. The roles of land tenure reforms and land markets in the context of population growth and land use intensification in Africa. Food Policy 2014, 48, 88-97. [CrossRef]

40. Qiao, F.; Rozelle, S.; Huang, J.; Zhang, L.; Luo, R. Road expansion and off-farm work in rural China. China Q. 2014, 218, 428-451. [CrossRef]

41. Cervellini, M.; Fiorini, S.; Cavicchi, A.; Campetella, G.; Simonetti, E.; Chelli, S.; Canullo, R.; Gimona, A. Relationships between understory species specialists and local management practices in coppiced forests-Evidence from the Italian Apennines. For. Ecol. Manag. 2017, 385, 35-45. [CrossRef]

42. Cook, S. From Rice Bowl to Safety Net: Insecurity and Social Protection during China's Transition. Dev. Policy Rev. 2002, 20, 615-635. [CrossRef]

43. Tao, R.; Xu, Z. Urbanization, rural land system and social security for migrants in China. J. Dev. Stud. 2007, 43, 1301-1320. [CrossRef]

44. Chen, J.; Yang, S. Rural Social Security System of China: Problems and Solutions. Stud. Sociol. Sci. 2014, 5, 32-37.

45. Zhao, Y. The Role of Migrant Networks in Labor Migration: The Case of China. Contemp. Econ. Policy 2003, 21, 500-511. [CrossRef]

46. Shi, X.; Heerink, N.; Qu, F. Choices between different off-farm employment sub-categories: An empirical analysis for Jiangxi Province, China. China Econ. Rev. 2007, 18, 438-455. [CrossRef]

(C) 2017 by the authors. Licensee MDPI, Basel, Switzerland. This article is an open access article distributed under the terms and conditions of the Creative Commons Attribution (CC BY) license (http://creativecommons.org/licenses/by/4.0/). 